\title{
REESCRIBIR LA FANTASÍA: FRANKENSTEIN DE ANGÉLICA LIDDELL
}

\author{
Laeticia Rovecchio Antón \\ Universitat de Barcelona \\ laeticia.rovecchio@gmail.com
}

Recibido: 31-08-2014

Aceptado: 19-11-2014

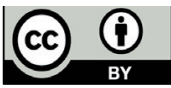

\section{RESUMEN}

La novela de Mary Shelley Frankenstein o el moderno Prometeo (1818) supone la creación de un nuevo mito popular muy presente en el imaginario colectivo gracias, en gran medida, a la labor cinematográfica. Muchas son las adaptaciones literarias o teatrales que han indagado en el carácter monstruoso del personaje desde prismas diferentes. La dramaturga Angélica Liddell, con su pieza poético-dramática titulada Frankenstein, propone un espectáculo de títeres que sirve de punto de partida para una profunda reflexión y actualización del mito y, en mayor medida, acerca de la relación entre el creador y su creación. En efecto, Liddell cuestiona la relación entre el «yo» y la alteridad al asociar la monstruosidad a un arquetipo constitutivo del ser humano.

Palabras clave: Monstruo, reescritura, Angélica Liddell, Frankenstein, teatro.

\section{ABstract}

Mary Shelley's novel Frankenstein; or, The Modern Prometheus (1818) involves the creation of a new popular myth very present in the collective imagination thanks, in large part, to film works. There are many literary or theatrical adaptations that have explored the monstrous nature of the character through different prisms. The playwright Angélica Liddell, with her dramatic-poetic piece entitled Frankenstein, proposes a puppet show that serves as a starting point for a deep reflection on and an update of the myth and, even moreso, about the relationship between the creator and his creation. In effect, Liddell questions the relationship between the ego and otherness, associating monstrosity to a human constitutive archetype. 
Keywords: Monster, rewrite, Angélica Liddell, Frankenstein, drama.

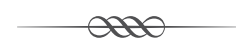

La primera versión de la novela Frankenstein o el moderno Prometeo de la joven Mary Shelley se publica en 1818, alcanzando un notable éxito, que se traduce en la proliferación de múltiples adaptaciones, en menos de una década, y las dos ediciones corregidas que publicará la autora en vida. En la cartelera teatral de la época, en 1823, Richard Brinsley Peake estrena Presumption: or the Fate of Frankenstein, pieza que la propia Shelley vio representada en el English Opera House, y, en 1826, se estrena el montaje Frankenstein or the Man and the Monster de Henry Milner. Dos acontecimientos que favorecen la difusión de la figura del monstruo en la cultura popular, aunque, sin duda, la película Frankenstein de James Whale (1931), protagonizada por el actor Boris Karloff, marca un hito fundamental en la construcción de un referente visual del mito que pervive hoy en día en el imaginario colectivo.

En esta disyuntiva, no es de extrañar que el protagonista de la novela de Shelley se haya convertido en un mito universal que, como tal, ha penetrado en el inconsciente cultural de las generaciones posteriores y ha dado lugar al nacimiento de un nuevo género basado en la fantasía, en el «merveilleux scientifique» (Todorov, 2005: 62), en lo que entendemos por ciencia ficción (Aldis, 1990). En efecto, tomando sustento en la mitología griega a través de la figura de Prometeo, Shelley consigue traspasar los límites de la actualización para generar, como apuntan Baldick y Levine, un nuevo mito basado en las preocupaciones de la modernidad, ya que «dramatizes certain doubts about the rewards of knowledge» (Baldick, 1987: 45) y se convierte en «a metaphor for our own cultural crises» (Levine, 1979: 3). La novela apela a un profundo cuestionamiento del ser humano, en su presencia y representación, así como en su relación con los otros miembros de la comunidad, puesto que promueve «un viaje que conduce al íntimo y doloroso sentimiento de una fragmentación insuperable; a la conciencia de una identidad monstruosa (hecha de partes) que se cuestiona a sí misma y busca -infructuosamente- la unidad del ser» (Burdiel, 2012: 95). La monstruosidad inicia, entonces, el diálogo entre un «yo» y la alteridad porque «[1]a novedad de Frankenstein es que nos hace ver al otro no desde el punto de vista de aquello en lo que coincidimos con él sino 
escuchar su propia voz desde la diferencia que expresa.» (Rodríguez Valls, 2011: 482).

Fruto de esta vitalidad son, sin duda, las múltiples adaptaciones de la novela de Shelley. En este sentido, el hecho de que las primeras fuesen obras teatrales evidencia la relación del teatro con los elementos fantásticos, pues desde el inicio de su historia abundan los artilugios que permiten la aparición de dioses, espectros, animales animados, robots, etc. Todo un despliegue técnico que favorece la ilusión de realidad, de «la verosimilitud de lo increíble» (Liddell, 1993b: 91), de estos personajes nacidos de la imaginación de sus autores; en otros términos, incide en la aparición de un componente sobrenatural en la puesta en escena. De hecho, en las propuestas dramáticas de las vanguardias históricas se aprecia una búsqueda, inspirada en los postulados de Henrich von Kleist (2005), por sustituir a los actores de carne y hueso por muñecos, que derivaría en los montajes de los creadores futuristas (Depero o Pampolini), dadaístas (Taeuber-Arp) o de la escuela de la Bauhaus (Schlemmer o Klee), pero, lejos de parecerse a espectáculos para un público infantil, las marionetas invocan directamente al mundo de los adultos.

En el ámbito hispánico, a finales del siglo xIx, empiezan a florecer textos que centran su atención en marionetas, muñecos, títeres, que se transforman en los verdaderos protagonistas de la acción. Prueba de ello, es la labor del dramaturgo Jacinto Benavente, quien en su Teatro fantástico (1892) y, en particular, con su pieza breve El encanto de una hora, otorga vida a dos figuras de porcelana que dialogan sobre el escenario. Ya entrados el siglo xx, Jacinto Grau se acerca al universo de los muñecos en su destacado El señor Pigmalión (1923), Valle-Inclán escribe el Retablo de la avaricia, la lujuria y la muerte (1924), cuyas obras breves mezclan actores y marionetas, o incluso García Lorca parece haber escrito su Amor de don Perlimplín con Belisa en su jardin (1928) para un espectáculo de títeres. Estos ejemplos ${ }^{1}$ muestran claramente el interés por crear personajes manipulados por el actor o el titiritero, que incluso pueden compartir escenario con personajes de carne y hueso, lo que enfatiza la dialéctica entre el creador y su creación -núcleo temático básico de la novela de Shelley-.

La propuesta teatral de Angélica Liddell (Figueres, 1966), en los inicios de su carrera dramatúrgica en la década de 1990, se enmarca justamente en esta tradición española y, más concretamente, su obra poético-dramática

1 El artículo de Checa (2009) ofrece un panorama sumamente clarificador sobre las diferentes obras que constituyen tanto el germen vanguardista del uso de muñecos y títeres en la escena teatral mundial como en el caso particular de España. 
Frankenstein. Esta obra, escrita en 1997 y estrenada en enero de 1998 en la sala Cuarta Pared de Madrid, ${ }^{2}$ fue creada para actores y títeres, siguiendo la técnica japonesa bunraku, aunque posteriormente en 2009 se publicaría como un poemario de versos libres. A pesar de su postura un tanto escéptica acerca del valor de Frankenstein en su currículo dramático, durante la presentación de la edición del libro en el Centre Cultural Blanquerna de Madrid el 16 de junio de $2009^{3}$-más de una década después de su escritura y estreno-, esta obra conecta directamente con el devenir dramatúrgico de la autora, ya que «[s]i trazamos una línea en el teatro de Angélica Liddell desde 1993 hasta el 2002 encontramos una temática común centrada en profundizar en los elementos familiares en todas sus vertientes -contratos religiosos, padres, hijos, pareja, procreación- que se llevará a cabo subvirtiendo sus órdenes hasta generar ritos desnaturalizados, "crimen"» (Eguía Armenteros, 2007: 176). Dentro de estas coordenadas temporales se sitúan las primeras creaciones de Liddell en las que el sexo y la muerte se conjugan continuamente: ${ }^{4}$ Dolorosa (1994) -una prostituta que ejerce su profesión en búsqueda de amor-, Morder mucho tiempo tus trenzas: las condenadas (1996) -un amor homoerótico entre Primera y Segunda dominado por la violencia frente a una tragedia inminente-, Suicidio de amor por un difunto desconocido (1999) -la violación de una joven, Blanquita, condenada a contraer matrimonio con un muerto- y La falsa suicida (2000) -una reescritura de los personajes shakespearianos Horacio y Ofelia de Hamlet desde una cabina de peep-show-. Además, la relación entre el creador y la

2 No he visto la representación del espectáculo en el momento de su estreno ni tampoco he localizado ninguna copia filmada, por lo que las referencias a la puesta en escena de la obra provienen de las diferentes reseñas de dicho estreno en 1998 y de las fotos, recogidas en el archivo Parnaseo de la Universitat de València, cuyo contenido está disponible en su página web: <http://parnaseo. uv.es/ars/autores/liddell/frankenstein/imagenes/imagen1.htm>. Al ser el teatro un género que no solo depende de un texto previamente fijado por su autor sino que necesita de la representación para adquirir su plenitud, y con mayor relevancia todavía si el texto y la dirección escénica son llevados a cabo por la misma persona -en 1993, junto a Gumersindo Puche, fundó la compañía Atra Bilis en la que realiza la dramaturgia, la puesta en escena y la actuación de sus espectáculo-, se vuelve sumamente productivo recurrir tanto a la obra escrita como a la puesta en escena. Por ello, durante todo el estudio haré referencias a ambos soportes para un pleno entendimiento del propósito de la dramaturga y directora Angélica Liddell.

3 «Con Frankenstein no me identifico en absoluto, me parece una cursilada espantosa. Eso... Era yo una cría, cuando piensas que todo lo que tienes que escribir tiene que tener que ver con la belleza y la muerte». Esta cita de la dramaturga corresponde a una transcripción del vídeo posteado por el propio centro cultural, a través de su canal de Youtube, el 20 de agosto de 2009, disponible en

$<$ https://www.youtube.com/watch?v=BgzowesfgoQ\&index=3\&list=PLC262D33FEAC85F21 > [Fecha de consulta: 11.11.2014]

4 Muchos son los textos que son todavía hoy en día inéditos (La condesa y la importancia de las matemáticas, 1990; El amor no se atreve a decir su nombre, 1994; Menos muertos, 1997; Ramargo y recordada y la voluntad de los insectos, 1998; y Agua y limonada en el Madison Square Garden, 1999) o que han conocido un estreno, pero no se han publicado (Greta quiere suicidarse, 1993; El jardín de las mandrágoras, 1993; La cuarta rosa; 1996; y Y tu mejor sangría, 2003). 
creación se prolonga en la deformidad del núcleo familiar, pautado por prácticas sexuales perversas, del Tríptico de la aflicción ${ }^{5}$-El matrimonio Palavrakis (2001), Once upon a time in West Asphyxia (2002) e Hysterica Passio (2003)-, que desembocará en su rechazo a la maternidad en la acción performativa Lesiones incompatibles con la vida (2003). Si bien Frankenstein pertenece a este primer ciclo de la dramaturga, arraiga la búsqueda de la monstruosidad en las prácticas sociales, puesto que «Liddell no describe los monstruos, sino que los conjura, los convoca; no habla sobre los monstruos, sino a través de ellos. [...] los montajes de Liddell revisten una forma inmediata y provocan un enfrentamiento directo e intenso con el tabú» (Hartwig, 2003: 68). ${ }^{6}$

En este sentido, la decisión de la dramaturga por crear, en su Frankenstein, un títere explicita su afán por hablar a través del monstruo. En el teatro bunraku, las marionetas son manipuladas por titiriteros, vestidos completamente de negro, visibles en el escenario. Así, Angélica González -nombre verdadero de la dramaturga que utiliza para diferenciar la actriz de la escritora y directora escénica-, junto a su compañero Gumersindo Puche manipulan, como advierten Itziar Pascual (1998) y Elena Hevia (1998), muñecos de aproximadamente un metro de altura hechos de látex. Según la propia dramaturga, la elección de usar títeres para la concepción de la reescritura del texto de Shelley no fue fruto del azar, sino que, gracias a las dimensiones de las marionetas que parecen casi humanas, pone en evidencia la relación próxima entre el creador y la creación, así como la monstruosidad subyacente de la propia criatura: «Aportan [los muñecos] más credibilidad a la hora de tratar al monstruo. Es una forma de expresión muy hermosa que encaja con la propuesta lírica que pretendo. Son seres creados por nuestras manos, y en cierto modo reproducíamos la historia de Víctor Frankenstein al dar forma a nuevas criaturas. Así podíamos sentirnos creadores en el sentido más primordial y literal» (Víllora, 2009: 10).

5 De hecho, para la puesta en escena de los tres espectáculos, Liddell recurre nuevamente a la imagen del muñeco: «El matrimonio Palavrakis, obra en la que la horizontalidad del suelo se ve sustituida por una montaña de cuerpos de muñecas de plástico con los miembros desarticulados [...] En Once upon a time in West Asphixia el techo está tapizado con osos de peluches colgados como en una barraca de feria. En Hysterica Passio numerosos hilos rojos unen a los personajes en escena a unas guirnaldas de luces de feria...» (Garnier, 2012: 127). Con ello, la dramaturga promueve una estética intensamente visual, que recuerda las instalaciones de la artista plástica francesa Annette Messager, que se caracteriza por presentar peluches y muñecos desmembrados. Ambas creadoras enfatizan y corrompen estos juguetes infantiles para demostrar el horror que encierra nuestra cotidianidad.

6 Entre estos temas tabúes que apunta Hartwig se puede destacar: las violaciones de las niñas en $Y$ cómo no se pudrió... Blancanieves (2005) o Yo no soy bonita (2005); la violencia de género en Enero (2006) o La casa de la fuerza (2009); la inmigración en $Y$ los peces salieron a combatir contra los hombres (2003) o Perro muerto en tintorería: Los fuertes (2007); o el abuso de poder en El año de Ricardo (2005). 
Liddell decide trabajar con el monstruo sin nombre ${ }^{7}$ de Shelley para reflexionar sobre diferentes conceptos -creador/criatura, belleza/fealdad, vida/muerte- para recoger el dolor y el horror de la humanidad. Al igual que la novelista inglesa, la dramaturga opta por reconstruir una historia lineal, ordenada cronológicamente desde el nacimiento hasta la persecución del monstruo después de la muerte de Elisabeth (curiosamente Liddell opta por un final más abierto sin un castigo, pues ni Víctor Frankenstein ni su criatura mueren). A través del moderno Prometeo, del plasticator que perpetúa la especie, aunque esta vez mediante el cuerpo de cadáveres humanos, Shelley desvela, justamente, la atracción que siente el individuo por la parte oscura de la humanidad, por nuestra monstruosidad -consensuada directamente con nuestra propia hipocresía que consiente la creación de dichos monstruos, aunque, finalmente, los repudian-. ${ }^{8}$ Al fin y al cabo, la escritora británica ofrece una profunda reflexión sobre la naturaleza humana, sobre el afán de creación que despertaba la revolución científica impulsada por el positivismo. Un afán de grandeza que necesariamente desemboca en castigo del y para el hombre, como son las múltiples muertes de la novela (el ciego, la niña, William, Elisabeth, Víctor, etc.) y que Liddell recoge para mantener un pulso en contra de la era globalizada del nuevo milenio.

\section{EL NACIMIENTO DE UN MONSTRUO}

Si nos fijamos en la definición de la RAE, el término monstruosidad acepta dos acepciones: «Desorden grave en la proporción que deben tener las cosas, según lo natural o regular» y «Suma fealdad o desproporción en lo físico o en lo moral». La idea de monstruosidad se define desde el físico, la moral y la estética, pues se asocia a la fealdad y la anormalidad, que pone de manifiesto la relación directa con el otro y, más concretamente, con su mirada sobre el objeto considerado monstruoso. En este sentido, la monstruosidad se enraíza en la dicotomía ancestral entre el Bien y el Mal, entre la empresa divi-

7 La tradición ha asociado el apellido del científico con el nombre de la criatura, por lo que se conoce como Frankenstein. No obstante, en el original británico, Shelley no da ningún nombre al monstruo, sino que se refiere a él mediante sustantivos como «demonio», «diablo», «monstruo», entre otros. En este sentido, Liddell, fiel a la fuente literaria, retoma la anonimia de la creación: «La tarea de los científicos consiste en hallar nuevos nombre/pero tú,/tú has olvidado poner nombre a lo que has creado» (Liddell, 2009a: 20).

8 Una muestra de esta atracción se puede encontrar en el proyecto fotográfico de la americana Diane Arbus, en la década de 1960, a través del cual, impulsada por su fascinación, retrata personajes marginales, monstruos de feria, enfermos mentales, y otros seres etiquetados por su aparente «anormalidad». 
na y su concepción del universo vertebrado en las contraposiciones de lo bello y feo, de lo bueno y malo, de lo verdadero y falso, por lo que su representación y existencia se transportan más allá de los límites fijados por la naturaleza, alejados de los patrones y los cánones diseñados por la sociedad. El hijo contranatura de Víctor Frankenstein, y, por extensión, el conjunto de monstruos construidos por el imaginario creativo, desde personajes metamorfoseados en la mitología griega o romana hasta los cyborgs o zombies en claro auge en los últimos años, sirve de punto de partida para el estudio de la condición humana.

Antes del despertar de la criatura, Shelley anticipa, durante su proceso de creación, el horrible resultado que se avecina. En efecto, a pesar de sus buenas intenciones por crear un hombre bueno y bello, rápidamente se ven truncadas por el uso de una escala demasiado gigantesca para concebir un ser humano bien proporcionado. Un hecho que Angélica Liddell también subraya:

Intentó que su creación fuera hermosa.

Que los miembros estuviesen proporcionados

y sus rasgos no carecieran de belleza.

¿Por qué se ha vuelto entonces tan repugnante al cobrar vida? (Liddell, 2009a: 19)

Si el experimento de Frankenstein es un éxito porque consigue crear vida humana a partir de otros cadáveres, solo lo es a medias, ya que su criatura es horriblemente fea. Tanto es el impacto que causa esta visión del cuerpo re-compuesto del monstruo que Víctor decide abandonarlo. A partir de este primer rechazo, se puede observar el afán de Angélica Liddell por deconstruir, en términos derridianos, esta visión horrorosa del cuerpo del monstruo al invertir las oposiciones jerárquicas que lo caracterizan, ya que la dramaturga plantea una historia que brinda una lanza a favor del ser marginado a la vez que condena al resto de la sociedad por su falta de comprensión hacia cualquier persona diferente:

Nuestro deber consistía en comprender al monstruo, no abandonarle aunque nos fallaran las fuerzas.

Impedir que el barro se secara y que el molde se partiera.

Mantener la luz encendida,

alimentar la obsesión, soñar con cerebros.

Acabarte para tener poder sobre ti. (Liddell, 2009a: 17) 
Esta referencia a la necesidad de comprensión del monstruo, es decir de ponerse en su lugar, favorece la lectura de la monstruosidad desde la estética de «lo sublime», propuesta por Burke en su Indagación filosófica sobre el origen de nuestras ideas acerca de lo bello y lo sublime y continuada por Kant en sus Observaciones sobre el sentimiento de lo bello y lo sublime y, posteriormente, en la Crítica de la facultad de juzgar. En efecto, a partir del siglo XvIII, la ética empieza a desligarse del arte y promueve una mayor libertad en sus manifestaciones. Con ello, la noción de belleza que regía el «buen gusto» de cada época deja espacio a la fealdad, a la distorsión y otras creaciones que no encajaban con los cánones establecidos (Danto, 2005). Lo sublime sirve, entonces, como vehículo para la producción de individualidades marginadas que se enfrentan a colectivos que las rechazan. El hecho de que la criatura de Frankenstein sea, a ojos del resto de la comunidad, un monstruo de dimensiones gigantescas, propio del «sublime matemático» kantiano, no solo otorga un componente siniestro al relato de Shelley, sino que este se acentúa con la decisión de Liddell de usar títeres para el espectáculo porque «está animada por un espíritu de transgresión, que, como en Foucault, Bataille, Blanchot y otros autores, trasciende los planos de lo político y de lo ético, y llega hasta la esfera de lo epistemológico y lo ontológico. Está planteando cuestiones que afectan al ámbito del conocimiento y de la propia existencia» (Gutiérrez Carbajo, 2009: 90).

Para Shelley, el monstruo se acerca más al demonio que a un individuo común: «La gigantesca estatura y su aspecto deformado, más horrendo que nada de lo que existe en la humanidad, me demostraron de inmediato que era el engendro, el repulsivo demonio al que había dotado de vida» (Shelley, 2012: 189-190). En cambio, Liddell presenta a un personaje feo, pero no por ello menos humano que el resto de sus lectores/espectadores, cuya monstruosidad se entiende como una construcción cultural que nace de un espacio simbólico de rechazo del otro por su componente diferenciador. Como apuntaba Freud, lo siniestro, el unheimlich, traduce aquello familiar que ha dejado de serlo por medio de la represión: «lo siniestro se da, frecuentemente y fácilmente, cuando se desvanecen los límites entre fantasía y realidad; cuando lo que habíamos tenido por fantástico aparece ante nosotros como real; cuando un símbolo asume el lugar y la importancia de lo simbolizado, y así sucesivamente» (Freud, 1991: 30). Y, ciertamente, la presencia en escena del títere evidencia este intento de desvanecer el límite entre la ficción y la realidad, por lo que lo siniestro, aliado a la sublimidad, confronta al individuo con el terror por el engendro de un Frankenstein demasiado humano. El monstruo se 
construye desde la heterología, ${ }^{9}$ se despliega desde la otredad, desde un lugar que no es el propio, desde una alteridad constitutiva. La criatura creada por Frankenstein no es un monstruo en sí mismo, sino que dicha etiqueta le ha sido impuesta por la sociedad:

No salgas.

Tu dulzura no coincide con el tamaño de tus dedos.

Ahí fuera eres cuerpo sobre todo,

cicatrices que ellos tomarán por surcos donde clavar las azadas. (Liddell,

[2009a: 24)

La relación entre Víctor y su creación muestra una fuerte interconexión porque cada uno necesita del otro para existir, para dar un sentido a sus vidas porque «los padres también son padres de sus hijos muertos» (Liddell, 2009a: $20)$, porque «Al fin y al cabo, la historia de los enemigos/ termina siendo una historia de amor» (Liddell, 2009a: 43). No obstante, el científico se deshace de su monstruo que erra por el bosque. Esta huida hacia la soledad marca un antes y un después en el desarrollo psicológico del ser marginado. Si su monstruosidad no parece ser de gran importancia mientras vive lejos de la humanidad, cuando se opera el re-conocimiento de la diferencia de su cuerpo respecto al resto de la comunidad se presagia el terrible final de la novela de Shelley porque «aún no sabe que matará» (Liddell, 2009a: 25), pero se intuye su venganza. El rechazo que sufre la criatura, consciente de esta diferencia física, pone de manifiesto una nueva interconexión con todo el conjunto social que le rodea, pues revela la monstruosidad encerrada en cada uno de los seres humanos:

Y debemos pensar como monstruos para que tú lo seas.

Hace falta valor para que nuestra cara retorcida aparezca en tu cara.

El monstruo ha sido nuestro espejo roto. (Liddell, 2009a: 17)

La imagen del espejo que utiliza Liddell confluye directamente con el original inglés, ya que, tanto en la novela de Shelley como en el drama, la mirada es crucial para entender la verdadera tragedia del monstruo cuyo rostro reflejado en el agua, tal Narciso, le propulsa a este estado de re-conocimiento sobre su condición. No obstante, la dramaturga traspasa la mera visualiza-

9 Término, procedente del griego hetero (lo otro) y logos (el conocimiento), acuñado por Georges Bataille, en torno a los años de 1930, en sus investigaciones sobre Sade, «La valeur d'usage de D.A.F. de Sade (Lettre ouverte à mes camarades actuels)» (1970: 59-60), y el fascismo «La structure psychologique du fascisme» (1970: 339-371). Posteriormente será desarrollado por Michel de Certeau en L'absent de l'histoire, publicado en 1973. 
ción física de los cuerpos que le rodea para apuntar que la monstruosidad se esconde en el interior de las personas.

El rechazo que sufre el monstruo es doblemente cruel porque, además de ser un sentimiento colectivo, parte de su propio padre, incapaz de transmitir amor y afecto a su criatura. En este sentido, el monstruo se erige, según los postulados de la psicología analítica desarrollada por Jung acerca del inconsciente colectivo (1991), como un arquetipo que define al individuo en su totalidad, pues, además de ser una imagen visual contundente e inquietante, representa la parte contingente del ser humano, el impulso exterior que deteriora la esencia de cada uno. Si la esencia de la criatura de Frankenstein se asemeja al sujeto universal, las características intrínsecas de la monstruosidad, de la perversión evidencian el proceso psíquico humano. La dramaturga, en su composición poético-dramática, a pesar de recalcar la deformidad, no ahonda en exceso en ella, por lo que el personaje se asemeja con mayor facilidad a un hombre cualquiera. Si bien se ve caracterizado por sus fuerzas y su proporción física descomunales, el horror que produce en los demás nunca permite al lector/espectador llevar a cabo ningún retrato realmente convincente de la totalidad de la figura del monstruo. ${ }^{10}$

A través de las palabras y los actos, el hombre deforme se convierte en «aullido» (Shelley, 2012: 289), en «grito» (Liddell, 2009a: 26). A pesar de poseer una buena capacidad de razonamiento no tiene ninguna posibilidad de convertirse en uno más, incluso el ciego lo acaba rechazando. La palabra no constituye ningún «remedio a la fealdad» (Liddell, 2009a: 26) porque «cuantas más palabras conoce más tristeza y temor siente» (Liddell, 2009a: 27), sino que sufre un proceso de corporeización, ya que encierra el significado de lo que caracteriza el físico del monstruo. Sin embargo, la dramaturga decide traspasar esta frontera y busca ensalzar la dulzura y la ternura que brota del personaje porque su maldad no es más que la reacción natural del odio que ha recibido desde su nacimiento.

\section{TERNURA Y SENSUALIDAD: LA IMPORTANCIA DEL CUERPO DEL OTRO}

Durante la representación de la obra, Liddell decide marcar la interconexión entre el creador y su creación mediante el uso del títere cuya figura se

10 Seguramente por este motivo Angélica Liddell haya decidido acompañar la puesta en escena de su composición poético-teatral de la técnica bunraku, puesto que si el texto encierra imágenes desdibujadas de la monstruosidad del engendro de Frankenstein, el títere evita cualquier confusión y sitúa su cuerpo deforme en el centro del discurso. 
plantea como una prolongación del propio cuerpo. Ambos sujetos emanan de una misma fuente $y$, necesariamente, comparten rasgos definitorios, a la vez que se contraponen. De alguna manera, la dramaturga le otorga cierta sustancia, cierto estar en el mundo, lo que permite llevar a cabo un diálogo directo con el otro. Pero no se trata de un diálogo verbal (puesto que el monstruo es un títere) sino corporal. Si en la técnica bunraku, los manipuladores solo forman parte del espectáculo porque son los encargados de dar vida a los muñecos, en la pieza de Liddell la actriz sale del anonimato e inicia una relación, un intercambio corporal con su creación, con su monstruo. De manera que la figura del titiritero pasa de ser un objeto a un sujeto de la acción, pues ya posee un papel en la obra. Liddell es mujer; el monstruo, un hombre. Dos características a simple vista básicas y perceptibles con una sola mirada, pero que permite mostrar la importancia del diálogo entre los dos cuerpos porque se extienden más allá de los límites del texto y asumen distintas lecturas posibles. En efecto, si en Frankenstein o el moderno Prometeo aparece un mundo de hombres en el que las mujeres ocupan una posición retraída, la dramaturga, en este caso la actriz, sustituye la figura del padre encarnado por Víctor Frankenstein para ser madre del engendro. Esta decisión entronca directamente con su afán por recalcar la ternura del monstruo y, de alguna manera, por reivindicar la importancia de la educación en la etapa de crecimiento de cualquier hijo -muy presente en el Tríptico de la aflicción-.

Liddell se acerca a la concepción desarrollada en Émile ou de l'éducation (1762) de Jean-Jacques Rousseau, ${ }^{11}$ que supone una revolución en la materia, a través de un joven huérfano sin madre y con un padre que muere prontamente -una grande coincidencia con el engendro de la criatura de Víctor creada sin la figura materna y con un padre que lo abandona desde su nacimiento-. El filósofo francés propone un nuevo modelo educativo basado en el espíritu crítico. El aprendizaje alcanza, entonces, un orden más intuitivo que se va modificando según la edad de los niños para integrar las normas sociales, lo que le permite no marginarse de la sociedad, puesto que conoce sus reglas, aunque pueda emitir un juicio personal acerca de estas. En la novela, el monstruo es capaz de leer, aprender una nueva lengua gracias a lo que encuentra en su entorno. Sin embargo, Rousseau (1966: 35-37) también advierte, en el

11 La dramaturga se aproxima a menudo a las obras de los grandes pensadores ilustrados. La idea del bufón de El neveu de Rameau de Diderot -se ha publicado una edición de Perro muerto en tintorería: los fuertes junto al clásico del filósofo francés- y la revisión de la sociedad de Le contrat social de Rousseau son hitos fundamentales para entender la radicalización de la dramaturgia de Angélica Liddell de los últimos años. 
Libro I, que «un homme abandonné dès sa naissance à lui-même parmi les autres serait le plus défiguré de tous», reivindicando la importancia del papel del amor de la madre en la educación de los hijos. Así, la dramaturga parece atender a las dos enseñanzas del francés al considerar necesario el estudio del hombre desde el hombre, en este caso la monstruosidad física como reflejo del alma -nuevamente la mirada $\mathrm{y}$, sobre todo, la imagen del reflejo opera un papel clave-, y al elegir la figura femenina como madre del títere.

A medida que avanza el espectáculo, la progenitora se va desvaneciendo, como también ocurre con los manipuladores del teatro bunraku que logran volverse invisibles a ojos del espectador para dejar pleno protagonismo a las marionetas, y subyace un componente erótico-sensual, por lo que la progenitora se convierte en una posible amante. Los dos cuerpos, el títere y la actriz, parecen tocarse, rebozar la frontera entre el artista creador y su criatura para entrar en un juego erótico peculiar. En la novela de Shelley, el deseo del monstruo de tener una mujer a su lado para huir de su soledad y, por consiguiente, obtener una acompañante a su imagen y semejanza, «necesariamente horrenda» (Liddell, 2009a: 38), da cuenta del ansia por tener una comunidad propia de la que no podrá ser rechazado porque:

Quedó tan lleno y tan hermoso aquel sexo que merece una mujer, aunque sea repugnante. (Liddell, 2009a: 38)

De manera que la voluntad de creación de una novia confiere al amor un papel fundamental -la sentencia final de la pieza de Liddell, recogida anteriormente en la exposición, es «la historia de los enemigos termina siendo una historia de amor»-, puesto que parece ser la única tabla de salvación posible:

Si no pueden sentir amor por él allá ellos, sentirán miedo.

Y será Víctor quien lo sienta con más fuerza.

En sus manos está.

¡Temed, temed la tiranía de los hijos!

Yo soy tu desgracia. Padre. (Liddell, 2009a: 33)

En otra obra de la dramaturga, Monólogo necesario para la extinción de Nubila Wahlheim y extinción (2009), ella misma adopta esta lectura sobre sus propias experiencias: «[m]i comportamiento es similar al del monstruo. Si no me aman haré todo lo posible para que sientan miedo. Soy la hija del doctor Frankenstein. No tengo nombre» (Liddell, 2009b: 89). Sin amor el monstruo no 
puede vivir porque la soledad es demasiado pesada; solo puede desencadenar odio y venganza. Retomando los postulados de Jung, la criatura, mediante este deseo de compartir su existencia con una mujer, se encuentra en un proceso de individuación efectivo. En otras palabras, el monstruo demuestra su afán de individualismo que, dada su peculiaridad física, sería la única manera de poder disfrutar de la vida.

Liddell impulsa las muestras de afecto, de cariño entre el monstruo y su manipuladora mediante caricias que representan una forma de comunicación entre dos cuerpos que no pueden usar la palabra para expresarse porque el uno es grito y la otra debe permanecer muda durante el desarrollo del espectáculo al asumir la figura del titiritero. La elección de la dramaturga permite entrever una manera de superar la primera barrera que marca la diferencia con el monstruo, ya que los cuerpos también sirven de medio de expresión. De ahí la importancia de que el cuerpo del títere sea imponente, sea como un ser humano mudo que se expresa a través de su comportamiento. Las menciones a la corporeidad del monstruo son constantes, lo que plasma dos planos de interpretación distintos: por un lado, se trata de un personaje con una sensibilidad y una ternura inigualable que acaricia, abraza, ama como se evidencia en el momento en el que estrecha la niña muerta, asesinada por otra persona; por otro lado, estos buenos sentimientos se contraponen con su aspecto físico, que le convierte en blanco de las miradas y los golpes:

Nunca crecerá porque no es un niño, tendrá siempre la misma estatura, las mismas proporciones.

No le importa quién es sino qué es. Dónde habitará el alma de este rompecabezas hecho de cadáveres.

En vez de unido parece estar descuartizado. (Liddell, 2009a: 23)

La mirada que se ejerce sobre el cuerpo también enlaza necesariamente con el concepto de lo sublime, pues marca una mezcla de deseo y de miedo, lo que Jean-Luc Nancy (1991) denomina el «sublime fini», consciente de los límites definitorios del ser humano, que desplaza la visión del horror desde el interior del sujeto hacia su propia corporeidad. La belleza se contrapone a la fealdad desde la mirada de uno mismo, pero también del otro. Siguiendo los postulados de Freud, se aprecia una clara referencia al discurso de un «yo» pautado por la «percepción-conciencia». Un enfoque que utiliza los estímulos tanto del mundo exterior como de la interioridad para construir el sujeto. En este sentido, el espejo se ve asociado, en términos psicoa- 
nalíticos, al reflejo de la imagen del mundo, pero no el mundo propiamente dicho, sino a una imagen que se hace de él. Según Lacan, se debe hacer una clara asociación con el mundo infantil, ya que el niño encuentra, a través del espejo, el reflejo de su "yo», de su aspecto físico, que se convierte en una especie de forma alienada que traduce cierto narcisismo propio del «yo» imaginario. De manera que el mirarse en un espejo se entiende como una experiencia básica de construcción del cuerpo -un elemento fundamental para convertir el ser en un todo-.

\section{Nuevos Prometeos}

Sin duda, la alusión directa, desde el título de Shelley, al mito de Prometeo marca un sustrato fundamental en la configuración del personaje de Víctor Frankenstein, que se perfila como un moderno Prometeo, como el titán que desafió a los dioses. El experimento de la creación de vida humana representa, tomando las palabras de Edgar Allan Poe, la «experiencia de los límites», es decir, la perdición y la destrucción del «yo». La empresa científica de este nuevo Prometeo nace de un profundo afán por sobrepasar los límites fijados por la naturaleza. Su capacidad para insuflar aliento a la criatura no solo desvela sus aptitudes técnicas, sino, justamente, su desafío al orden natural. De ahí que, inevitablemente, Víctor Frankenstein deba ser castigado por su osadía al alterar el orden natural. Pero la novelista decimonónica modifica la condena del personaje, pues los dioses no toman cartas en el asunto, al ser su propia criatura la que asume este papel. Así pues, Mary Shelley lleva a cabo una dura crítica en contra del positivismo de su época, en contra de la evolución científica que florece a partir del siglo xIx, fruto de las revoluciones industriales que conocerán muchos países europeos, en contra del denominado mito del progreso:

Si para Victor Frankenstein el paso de la pseudociencia a la ciencia conlleva el triunfo en la empresa que le venía preocupando desde su niñez, la creación de la vida, para Mary Shelley la Ciencia con mayúsculas muestra sus fallas, de ahí que, como primera novela de ciencia ficción, Frankenstein, o el moderno Prometeo cuestione, como la hará posteriormente toda una tradición literaria variada y rica, los adelantos científicos que, en este contexto concreto, han desafiado la naturaleza de un Dios creador y, por tanto, sólo pueden conducir a la destrucción. (Pulido Tirado, 2012: sp) 
En la novela, la ciencia recibe un tratamiento moralizante, ya que se ve vencida por su propio fruto en contra de la hybris, el orgullo y la soberbia del ser humano. En el caso de la obra dramática de Liddell también se percibe una dura crítica en contra del devenir de nuestra sociedad, pues, como apunta Heredia, el fin de milenio se caracteriza por «la desarticulación de la idea de progreso, de la emergente fragmentación del sujeto, de la crisis del núcleo familiar, de la noción globalizadora» (citado por Eguía Armenteros, 2007: 176). Esta fractura entre la tradición y el progreso, entre la percepción de un sujeto cada vez más fragmentado en la era de la globalización, evidencia el afán de la dramaturga por volver su mirada hacia este arquetipo junguiano, hacia una tradición más ancestral y común a todos los seres humanos. De hecho, la voluntad de crear un espectáculo de títeres marca también el legado de la tradición teatral, del ritual -en clara consonancia con el pensamiento de Artaud- al contraponerse al uso de otro artilugio que emulara la monstruosidad del hijo de Víctor. Sin embargo, Liddell no castiga directamente a ninguno de los dos personajes. Si bien es cierto que las muertes del ciego, de la niña, de William y Elisabeth aparecen retratadas, Víctor y Frankenstein salen ilesos de sus hazañas, puesto que la pieza se cierra con el momento de la persecución entre ambos. Este final abierto produce un intenso escalofrío porque pone de manifiesto que el peligro sigue todavía acechando fuera.

La influencia del mito de Prometeo empara las dos figuras masculinas protagonistas, ya que tanto el científico como el propio monstruo se aparentan al plasticator. Ambos, aunque partiendo de dos motivaciones distintas, quieren concebir un nuevo ser artificial. Esta cercanía entre los dos hombres pone de relieve la presencia de un tema recurrente en las letras victorianas, la figura del doble, en obras como El extraño caso del doctor Jekyll y el señor Hyde (1886) de Robert Louis Stevenson o El retrato de Dorian Gray (1890) de Oscar Wilde, entre otras. Para entender esta figura del doble, tanto en el Frankenstein de Shelley como de Liddell, es fundamental tomar en consideración, nuevamente, la importancia de la mirada del otro sobre el propio sujeto. El reflejo del alma de los personajes se traslada a la imagen del doble porque este se convierte en su alter ego o, mejor dicho, su alter ídem. En este sentido, el monstruo es un espejo sobre el que se proyecta la imagen más deshumanizada, los sentimientos más negativos de Víctor:

Él no quiere la libertad.

Quiere un nombre, para ensuciarlo o limpiarlo. 
Pero te arrebatará el tuyo.

Te arrebatará el nombre y escucharán Frankenstein,

y Frankenstein será el monstruo.

Y nadie, nadie se acordará de ti,

Víctor Frankenstein. (Liddell, 2009a: 32)

Además, el hecho de que la tradición haya asociado el nombre del monstruo con su progenitor también pone de manifiesto esta lectura del desdoblamiento de la figura del creador, que la dramaturga usa, «Frankenstein se apiada de Víctor Frankenstein» (Liddell, 2009a: 35), para legitimar la relación filial entre ambos, para enfatizar la importancia del nombre como marca distintiva de una persona. Esta distinción entre padre e hijos, fundamental en el desarrollo dramatúrgico posterior de Liddell, revela un nuevo desdoblamiento presente en la novela de Shelley: «la interpretación del tema del doble como una versión del tema de la maternidad. El monstruo que Mary inventa puede verse también como una interpretación simbólica de la tiranía de la maternidad sobre la mujer» (Ferré, 1992: 35). De hecho, en Frankenstein se aprecia esta semilla del deseo de no maternidad, desarrollada en Lesiones incompatibles con la vida, de la dramaturga:

Nunca hijos.

Nunca infectar un vientre.

Nunca más sangre de tu sangre.

Nunca lagrimeos a media noche, babas, fiebres, mierda, orín.

Nunca olor a colonia y leche.

¡Nunca!

Miedo al cuerpo blanco que llora y pide. (Liddell, 2009a: 39)

En el caso de su reescritura de la novela de Shelley, su rechazo a la maternidad pone de manifiesto el origen de la maldad de los dos hombres protagonistas. Asimismo, Liddell ahonda en este juego desdoblado entre los personajes, en este caso entre la actriz-manipuladora y el monstro-títere, ambos unidos por unos hilos, mediante una carga erótico-sensual de los dos cuerpos. En el escenario, son dos elementos claramente perceptibles que parecen diferenciar el sujeto que representa del objeto representado. No obstante, Liddell decide incluir al sujeto manipulador como parte del espectáculo, lo que lo convierte, de alguna manera, también en objeto al representar la prolongación de su cuerpo: «Actor y rol, subjecte i objecte, són substancialment inseparables» (Knoedgen, 2003: 81). 
Al comprobar toda esta serie de roles desdoblados entre el creador y su creación, tanto en un único cuerpo como en dos, ¿no se podría extender esta reflexión a cualquier ser humano? Efectivamente, el propósito de Liddell recae en esta necesidad de evidenciar la monstruosidad de todos los individuos. $\mathrm{Si}$, en un principio, la aparición de los títeres puede suponer una distancia para la plena identificación con el monstruo, pronto se supera la barrera porque representa una parte de nosotros:

Justament pel fet que la representació del teatre de figures és escindida, el subjecte escènic pot triar lliurament la seva forma d'aparició fora o dins del rol. Però el fet que la representació és contradictòria -aquesta llibertat «fantàstica» que és al mateix temps perceptible des del punt de vista funcional $i$ autorial-permet a l'espectador d'aquest teatre de figures «retroactiu» participar d'una creació inacabable: el comportament humà es converteix en matèria. La materia comença a actuar. Els objectes esdevenen contrincants. (Knoedgen, 2003: 88)

Al tratar de la relación entre Víctor y su engendro se ha puesto de manifiesto que el uno se siente hijo mientras que el otro huye de su papel de padre. A través de ello, Angélica Liddell presenta una dura crítica en contra del abuso de poder de los padres sobre los hijos y, por extensión, sobre el conjunto de la sociedad, puesto que imposibilita una plena elección vital de sus habitantes.

Una vez dejado en el mundo, Frankenstein no puede seguir la vida que quiere, sino que su destino está predestinado a un trágico final, al mismo tiempo que su criatura está, desde el inicio, condenada al rechazo social porque «el muñeco de Frankenstein solo podrá entablar relación frente a la indiferencia de su entorno privado mediante juegos rituales del exceso -asesinatos, mutilaciones- que conducirán finalmente a todos a la misma Pasión, una ceremonia de martirio final entre creador y ser creado con la que se identificarán» (Eguía Armenteros, 2007: 179). Se trata de una visión horrorosa que convierte al ser humano (creador de monstruos) en sujeto capaz de controlar no solo el destino del resto de la comunidad, sino también de otro cuerpo para manipularlo a su antojo -muestra de ello es la elección, justamente, del títere-, lo que se asemeja, a su vez, a la figura de Prometeo. En una pieza anterior a la reescritura del clásico de Shelley, Leda (1993), Liddell recuerda que el ser humano está compuesto de diferentes materias orgánicas: «Un poco de carne, un poco de huesos, un poco de pelo, un poco de sangre y un poco de mierda. ¿Qué otra cosa pretendéis ser?» (1993a: 152). A su vez, en su acción performativa Boxeo 
para células y planetas. El miedo a la muerte como origen de la melancolía (2006), Liddell sigue en esta misma línea porque construye su espectáculo partiendo de la idea de que todos estamos «hechos de la misma materia que los cadáveres» (Liddell, 2006:12 3). En este aspecto, cualquier cuerpo humano puede trocearse en retazos que recuerdan la materia cadavérica del monstruo, por lo que todos podemos ser posibles monstruos, posibles Frankensteins, posibles Prometeos. Si Liddell decide no castigar con la muerte a sus dos protagonistas, significa que el monstruo sigue entre nosotros, puesto que en nosotros está la semilla de la monstruosidad, el afán de crear constantemente sujetos (los hijos) y objetos (los productos de consumo) que dependan de nuestros criterios y, por consiguiente, de nuestra parte más malévola porque, retomando las palabras de la dramaturga, «aguardan [o, mejor dicho, aguardamos] aún muchas horas de sufrimiento» (Liddell, 2009a: 42). Sin castigo, no hay redención y sin redención, no hay descanso posible para la humanidad, condenada a errar para perseguir, junto a Víctor, a la monstruosa creación.

\section{BIBLIOGRAFÍA:}

Aldis, W. Brian (1990): Frankenstein desencadenado, Ediciones Minotauro, Barcelona.

BAldick, Chris (1987): In Frankenstein's Shadow. Myth, Monstrosity, and the $19^{\text {th }}$ Century Imagination, Clarendon Press, Oxford.

Bataille, Georges (1970): Euvres complètes, 2 tomos, Gallimard, París.

Burdiel, Isabel (2012): «Introducción», en Mary W. Shelley, Frankenstein o el moderno Prometeo, Cátedra, Madrid.

Certeau, Michel de (1973), L'Absent de l'histoire, Mame, París.

CHeCA, Julio (2009): «Lo fantástico y el teatro español del siglo XX», en Teresa López-Pellisa y Fernando Ángel Moreno (eds.), Ensayos sobre ciencia ficción y literatura fantástica, Universidad Carlos III de Madrid, pp. 152-177.

Danto, Arthur C. (2005), El abuso de la belleza: la estética y el concepto del arte, Paidós, Barcelona.

Eguía Armenteros, Jesús (2007): «Angélica Liddell y la tragedia de la indiferencia», Teatro: Revista de estudios escénicos, Segunda época, n²1, Universidad de Alcalá, Madrid, pp.173-200.

FERRÉ, Rosario (1992): «Frankenstein: una versión política del mito de la maternidad», Debate feminista, México. Disponible en <http://www.debatefeminista.com/PDF/Articulos/franke1042.pdf> [11.11.2014]

Freud, Sigmund (1991): Lo siniestro, Hesperus, Barcelona.

12 Esta obra se publica en soporte digital sin especificarse ninguna fecha concreta de publicación, por lo que hago referencia a la fecha de estreno del espectáculo. 
HaRtwig, Susanne (2003): «¿Alteridad monstruosa? La estética de Angélica Liddell», en Susanne Hartwig y Klaus Pörtl (eds.), Identidad en el teatro español e hispanoamericano contemporáneo, Valentia, Francofurti Moenani, pp. 61-71.

GARNIER, Emmanuelle (2012), «El "espíritu de lo grotesco" en el teatro de Angélica Liddell», Signa, 21, pp. 115-136.

Gutiérrez CARbajo, Francisco (2009), «El animal no humano en algunas obras teatrales actuales», Anales de literatura española contemporánea, vol. 34, n², pp. 67-92.

Henríquez, José (1998): «Elegía romántica», La guía del ocio, disponible en <http:// parnaseo.uv.es/ars/autores/liddell/frankenstein/prensa/prensa4.htm> [11.11.2014]

Hevia, Elena (1998): «El monstruo títere», El periódico, disponible en < http://parnaseo. uv.es/ars/autores/liddell/frankenstein/prensa/prensa5.htm> [11.11.2014]

Jung, Carl Gustav (1991), Arquetipos e inconsciente colectivo, Paidós, Barcelona.

KLEIST, Henrich (2005): Sobre el teatro de marionetas y otros ensayos de arte y filosofía, Ediciones Hiperión, Madrid.

KNOEDGEN, Werner (2003): El teatro imposible: per una fenomenologia del teatre de figures, Institut del Teatre, Barcelona.

Levine, George (1979): «The Ambiguous Heritage of Frankenstein», en George Levine y Ulrich C. Knoepflmacher (eds.), The Endurance of Frankenstein: Essays on Mary Shelley's Novel, University of California, Berkeley, pp. 3-30.

Liddell, Angélica (1993a): Leda, Nuevo Teatro Español, Centro Nacional Nuevas Tendencias Escénicas, Madrid, pp. 94-155.

(1993b): «El teatro de la pasión», en Angélica Liddell Zoo y Juan Mayorga, Leda y El traductor de Blumemberg, Nuevo Teatro Español, Centro Nacional Nuevas Tendencias Escénicas, Madrid, pp. 87-93.

(2006): «Boxeo para células y planetas. El miedo a la muerte como origen de la melancolía", Artea: investigación y creación, disponible en <http://artesescenicas. uclm.es/archivos_subidos/textos/242/angelicaliddell_boxeocelulas. pdf $>$ [11.11.2014]

(2009a): Frankenstein y La historia es domadora del sufrimiento: 2006, Eugenio Cano Editor, Fuente del abanico, Sigüenza.

(2009b): Monólogo necesario para la extinción de Nubila Wahlheim y extinción, Artezblai, Bilbao.

(2011): Tríptico de la aflicción: El matrimonio Palavrakis, Once upon a time in West Asphixia. O hijos mirando al infierno, Hysterica Passio y Lesiones incompatibles con la vida, Artezblai, Bilbao.

Muñoz-Rojas, R. (1998): «Estreno de un musical y una obra de títeres. Dos montajes sobre Frankenstein ofrecen visiones diferentes del mito", El País, disponible en <http://elpais.com/diario/1998/01/08/madrid/884262264_850215.html> [11.11.2014]

Nancy, Jean-Luc (1991): Une pensée finie, Éditions Galilé, París.

PAscuAl, Itziar (1998): «Alma de lártex. Atra Bilis resucita el monstruo de Shelley con la técnica Bunraku», Metrópoli, disponible en 
<http://parnaseo.uv.es/ars/autores/liddell/frankenstein/prensa/prensa1.htm> [11.11.2014]

PÉrez de Olaguer, Gonzalo (1998): «Frankenstein y la mujer-vampiro se citan en Artenbrut. Dos espectáculos de 'monstruos' en el Festival de Teatre Visual i de Titelles», El periódico, disponible en

<http://parnaseo.uv.es/ars/autores/liddell/frankenstein/prensa/prensa8. htm> [11.11.2014]

Pulido Tirado, Genara (2012), «Vida artificial y literatura: mito, leyendas y ciencia en el Frankenstein de Mary Shelley», Tonos digitales. Revista de estudios filológicos, Murcia, disponible en <http://www.um.es/tonosdigital/znum23/secciones/ estudios-24-vida_artificial.htm $>$ [11.11.2014]

Rodríguez VAlls, Fernando (2011): «El Frankenstein de Mary Shelley (1797-1851)», Thémata. Revista de filosofía, no 44, Sevilla, pp. 473-484. Disponible en <http://institucional.us.es/revistas/themata/44/29\%20RodriguezValls.pdf> [11.11.2014]

Rousseau, Jean-Jacques (1966): Émile ou de l'éducation, GF: Flammarion, Paris.

Shelley, Mary W. (2012): Frankenstein o el moderno Prometeo, Cátedra, Madrid.

Todorov, Tzvetan (2005): Introduction à la littérature fantastique, Éditions du Seuil, París.

Víllora, Pedro (1998), «Frankenstein el monstruo distante», Ajoblanco, n 105, p. 91. (2009): «Ayer y hoy de Angélica Liddell», en Liddell, Angélica (2009): Frankenstein y La historia es domadora del sufrimiento: 2006, Eugenio Cano Editor, Fuente del abanico, Sigüenza, pp. 7-11. 